\title{
Axial Lumbar Interbody Fusion-A Critical Analysis
}

\author{
Dr Shashivadhanan \\ Neurosurgeon, Army Hospital Research \& Referral Center, Delhi, India 110010
}

\begin{abstract}
Numerous open and minimally invasive techniques have been developed but all of these approaches experience the same shortcomings related to biomechanics or inherent iatrogenic destabilization [16]. In an attempt to alleviate many of the limitations of previous lumbar fusion techniques, a pre-sacral approach to the lumbosacral junction has been investigated. The axial lumbar interbody fusion (AxiaLIF) system (TranS1, Inc., Wilmington, NC) combines a minimally invasive technique with a novel corridor approach. A total of three patients were evaluated I this study. Results were compared preoperatively and following the surgery at 3 and 6 months. There was a significant improvement in the pain scores. The Axial lumbar interbody fusion is a feasible procedure which will require long term studies before it can be validated as a standard technique for lumbar fusion.
\end{abstract}

Keywords: Axial Lumbar Inter body Fusion

\section{Aim}

To analyze the feasibility and efficacy of percutaneous 360 degree Axial lumbar interbody fusion as a standard procedure for lumbar fusion.

\section{Materials and methods}

The study was conducted in a Government tertiary care hospital of India. Three patients were offered this procedure. The patients included in this study had at least two years of intractable pain. They had already tried all other modalities of treatment for low back pain. On radiology, the pathology was limited to L5S1 segment only. Up to Grade two spondylolisthesis cases were included in this study.MRI of the lumbosacral spine were carried out and all those with abnormal sacral anatomy, like flat or hooked sacrum, very less presacral fat or anomalouspresacral vessels were excluded from this study.A total of three patients were subjected to this study.In one patient with L5S1 Spondylolysis it was offered as a standalone procedure and in two patients with grade 1spondylolisthesis L5 over S1 + the procedure was supplemented with posterior pediclescrew fixation. In the preoperative planning the MRI sagittal images were reviewed for trajectory planning. Dynamic XRays covering lateral views were done of the lumbosacral spine to look for any translational mobility of the diseased segment. In the preoperative preparation, bowel was prepared, informed consent was taken which included consent to conduct any alternative procedure in case the proposed procedure failed. Through a small para-coccygeal incision, a pre-sacral corridor was percutaneously created for access to the anterior lumbosacral body and, subsequently, to the L5 - S1 intervertebral space. The AxiaLIF system includes instruments for creating a small pre-sacral axial track to the L5 - S1 vertebral bodies for the insertion of bone graft material into the disc space. The device also includes an anterior fixation rod that is implanted through the same track. In one patient it was offered as a standalone procedure while in other two, pedicle screw fixation was done. The pre and postoperative neurological status, radiology and pain scores were compared.

\section{Observation}

Following the procedure no patient developed any complication or any Neurological deficit. The visual analog score which was 8 before the procedure improved to 4 at 3 months and subsequently at 6 months following the surgery. The imaging with MRI showed satisfactory placement of implant with no evidence of fresh neural compromise. Marked clinical improvements were realized in back pain severity with no additional morbidity.

\section{Result}

Percutaneous 360 degree Axial lumbar interbody fusion technique achieves satisfying therapeutic effects in the short term, although it has fairly narrow indication and needs long-term follow-up observation before it can be validated as a standard procedure for lumbar fusion. The procedure offers the advantage of being a minimally invasive procedure for L5 S1 inter body fusion. It maintains the integrity of the bilateral facet joints, the anterior/posterior longitudinal ligament, and the annulus fibrosus and other support structure which provide strong ligament support for inter body fusion.

\section{Discussion}

Lumbar spine is a finely balanced biomechanical wonder that relies on the integration of intervertebral height, joint mobility proprioception, muscle balance and osseoligamentous constraint to allow us to function without pain [17] This is the guiding philosophy of Axial Lumbar Interbody fusion as it attempts to immobilize the diseased segment with minimal destruction of the surrounding soft tissue structures.

Interbody fusion (arthrodesis) in the lumbar spine is performed to treat painful symptoms caused by instability of the vertebrae, such as spondylolisthesis, spinal stenosis, or degenerative disc disease [3]. Methods of spinal fusion include procedures in which bone grafts or metal implants are placed either anteriorly, posteriorly, or laterally. However, insertion of these implants is not without surgical risk. Numerous open and minimally invasive techniques 


\section{International Journal of Science and Research (IJSR) \\ ISSN (Online): 2319-7064}

Index Copernicus Value (2015): 78.96 | Impact Factor (2015): 6.391

have been developed but all of these approaches experience the same shortcomings related to biomechanics inherent iatrogenic destabilization. In an attempt to alleviate many of the limitations of previous techniques, a pre-sacral approach to the lumbosacral junction has been investigated in other countries. Transaxial anterior lumbar interbody fusion is an emerging minimally invasive spinal fusion procedure used to treat patients with chronic lower back pain (Ollendorf, et al., 2011)[4] This procedure is an alternative to traditional fusion techniques that utilize anterior or posterior approaches to directly expose the lumbosacral spine. In the case of transaxial anterior lumbar interbody fusion the spine is accessed percutaneously via the anterior surface of the sacrum. The axial lumbar interbody fusion (AxiaLIF) system (TranS1, Inc., Wilmington, NC) combines a minimally invasive technique with a novel corridor approach $[1,2]$. Proponents of this approach report minimal risk to adjacent vital structures and no annular disruption [5, $6,9.10,11,12,14]$. The AxiaLIF system was cleared for marketing through the Food and Drug Administration (FDA) $510(\mathrm{k})$ process [1]. The AxiaLIF percutaneous lumbar interbody fusion procedure may provide an alternative access route to the L5 - S1 inter-space in those patients who may have unfavorable anatomy or contraindications to the traditional open anterior approach[8.9.10, 13].This procedure offers the advantage of causing minimal soft tissue disruption of the Osseo ligamentous structures.It provides an alternative route for those patients with unfavorable anatomy. Theoretically allows better biomechanical fusion and adjacent level motion preservation. In case one is planning the posterior approach also, then both procedures can be performed in the same sitting. This procedure also has certain limitations in that it is applicable to only a certain select group of patients. Its role as a standalone procedure is debatable. Like any new minimally invasive procedure this has a learning curve. The long term functional outcomes are yet to be seen as current published literature and trials are inconclusive. Guidance from the National Institute for Health and Clinical Excellence (NICE, 2011) concluded that current evidence on the efficacy of transaxialinter body lumbosacral fusion is limited in quantity but shows symptom relief in the short term in some patients[7].

\section{Conflict of Interest}

Nil

\section{References}

[1] U.S. Food and Drug Administration (FDA). TranS1® AxiaLIF $^{\mathrm{TM}}$ System. 510(k) Summary. K050965. TranS1, Inc. Wilimington, NC. Rockville, MD: FDA; June $14,2005 . \quad$ Available at: http://www.fda.gov/cdrh/pdf5/K050965.pdf. Accessed September 19, 2008.

[2] TranS1. For surgeons AxiaLIF: Indications, contraindications, and warnings [website]. Wilmington, NC: $\quad$ TranS1; $2008 . \quad$ Available at:http://www.trans1.com/surgeons_axialif_indications. html. Accessed September 19, 2008.

[3] Resnick DK, Choudhri TF, Dailey AT, et al; American Association of Neurological Surgeons/Congress of
Neurological Surgeons. Guidelines for the performance of fusion procedures for degenerative disease of the lumbar spine. Part 11: Interbody techniques for lumbar fusion. J Neurosurg Spine. 2005;2(6):692-699.

[4] Marotta N, Cosar M, Pimenta L, et al. A novel minimally invasive presacral approach and instrumentation technique for anterior L5-S1 intervertebral discectomy and fusion: Technical description and case presentations. Neurosurg Focus. 2006;20(1):E9.

[5] Bohinski RJ, Jain VV, Tobler WD. Presacral retroperitoneal approach to axial lumbar interbody fusion: A new, minimally invasive technique at L5-S1: Clinical outcomes, complications, and fusion rates in 50 patients at 1-year follow-up. SAS J. 2010;4(54-62.

[6] Leopardi D. Transaxial lumbar interbody fusion. Horizon Scanning Technology Prioritising Study. Canberra, ACT: Australia and New Zealand Horizon Scanning Network; April 2010.

[7] National Institute for Health and Clinical Excellence (NICE). Transaxialinterbody lumbosacral fusion. Interventional Procedure Guidance 387. London, UK: NICE; March 2011.

[8] Tobler WD, Ferrara LA. The presacral retroperitoneal approach for axial lumbar interbody fusion: A prospective study of clinical outcomes, complications and fusion rates at a follow-up of two years in 26 patients. J Bone Joint Surg Br. 2011;93(7):955-960.

[9] Zeilstra DJ, Miller LE, Block JE. Axial lumbar interbody fusion: A 6-year single-center experience. ClinInterv Aging. 2013;8:1063-1069.

[10] Gundanna MI, Miller LE, Block JE. Complications with axial presacral lumbar interbody fusion: A 5-year postmarketing surveillance experience. SAS Journal. 2011;5(3):90-94.

[11]Lindley EM, McCullough MA, Burger EL, Brown CW, Patel VV. Complications of axial lumbar interbody fusion. J Neurosurg Spine. 2011;15(3):273-279.

[12] Gerszten PC, Tobler WD, Nasca RJ. Retrospective analysis of L5-S1 axial lumbar interbody fusion (AxiaLIF): A comparison with and without the use of recombinant human bone morphogenetic protein-2. Spine J. 2011;11(11):1027-1032.

[13] Gerszten PC, Tobler W, Raley TJ, et al. Axial presacral lumbar interbody fusion and percutaneous posterior fixation for stabilization of lumbosacral isthmic spondylolisthesis. J Spinal Disord Tech. 2012;25(2):E36-E40.

[14] Marchi L, Oliveira L, Coutinho E, Pimenta L. Results and complications after 2-level axial lumbar interbody fusion with a minimum 2-year follow-up. J Neurosurg Spine. 2012;17(3):187-192.

[15] Patil SS, Lindley EM, Patel VV, Burger EL. Clinical and radiological outcomes of axial lumbar interbody fusion. Orthopedics. 2010;33(12):883.

[16] FritzellP, et al:2001 Volvo Award Winner in clinical studies :Lumbar fusion versus nonsurgical treatment for chronic low back pain:amulticentric randomized controlled trial from the Swedish lumbar Spine Study Group. Spine(Phila Pa 1976)26:25212532; discussion2532-2524, 2001.

[17]Eric A K Mayer. Muscular support of the spine: Spine Surgery Techniques, Complication avoidance, and 
Management. Edward C Benzel: 2012; Vol 1(third Edition) Chapter 6 pg 69.

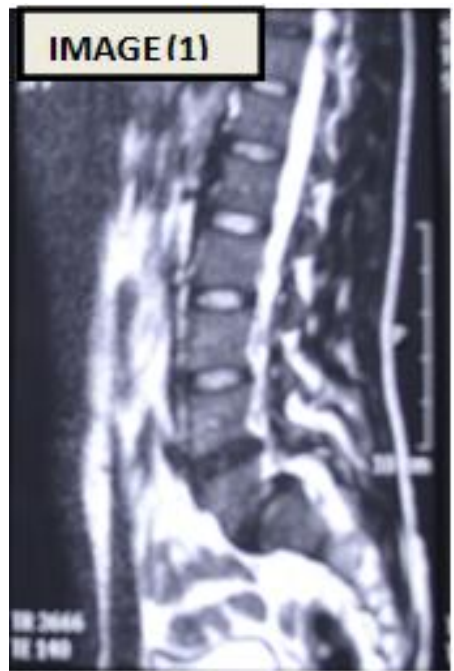

Image (1) Preoperative T2 Weighted sagittal view image of the lumbosacral spine showing grade 2 spondylolisthesis.

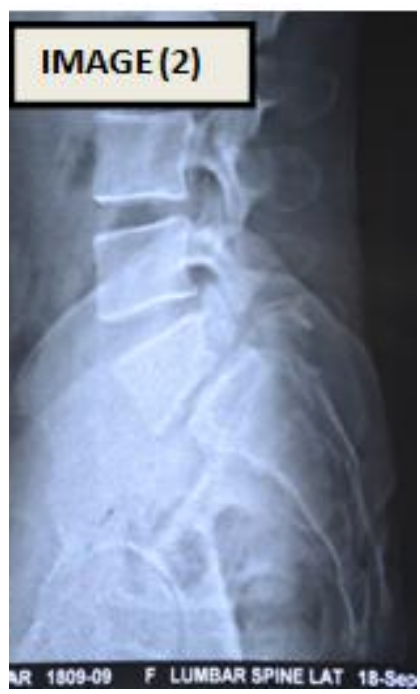

Image (2): Lateral view Plain X-Ray showing the bony outline of the same patient with Grade 2 spondylolisthesis L5 Over S1.

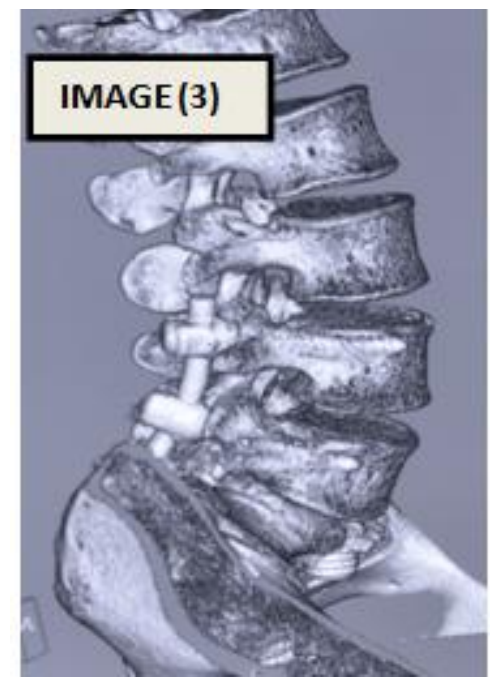

Image (3): Postoperative 3D reconstruction CT image with implant in situ.

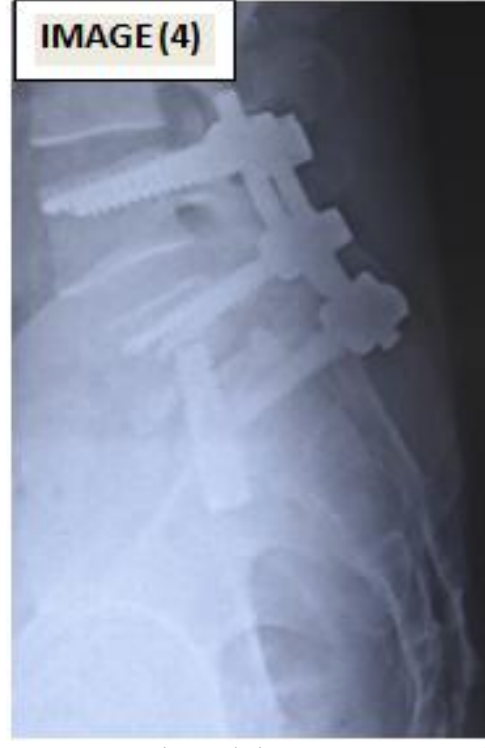

Image (4) Postoperative Plain X-Ray Lateral view with implants in situ

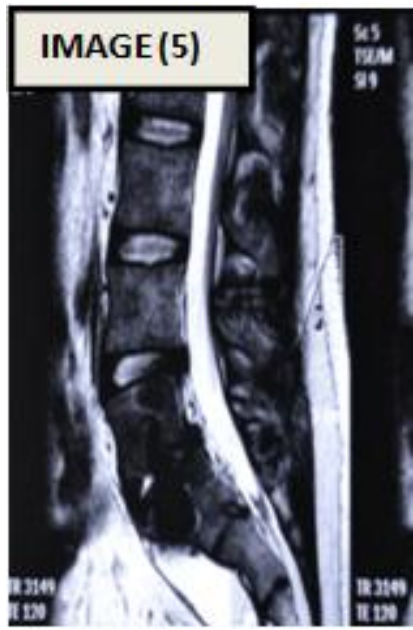

Image (5) Postoperative MRI T2 weighted Sagittal image with implant in situ where it was offered as a stand alone procedure for L5 S1 Spondylolysis.

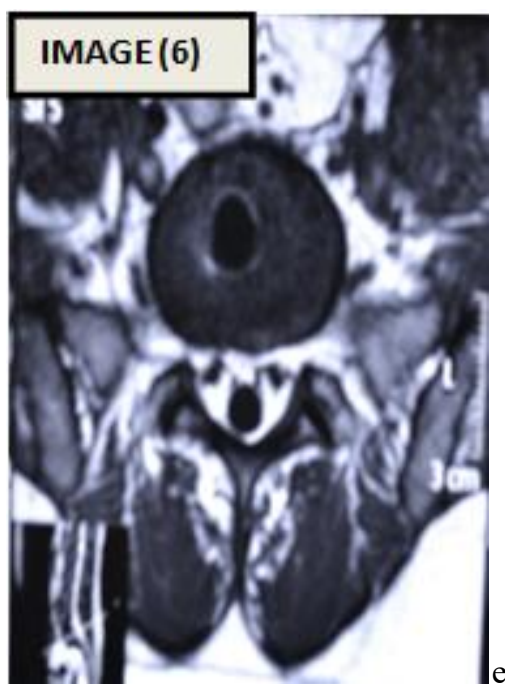

Image (6) Postoperative MRI T2 weighted axial view of the same patient showing the implant within the vertebral body

Volume 6 Issue 1, January 2017

www.ijsr.net 